\title{
Pengaruh Variasi Bentuk Potongan Agregat Bambu Petung Terhadap Berat Jenis dan Kuat Tekan Beton Ringan
}

\author{
Yoga Putra Darmansyah ${ }^{l}$; Farlin Rosyad ${ }^{2}$ \\ ${ }^{1,2}$ Program Studi Teknik Sipil, Universitas Bina Darma, Palembang, Indonesia \\ ${ }^{2}$ farlin.rosyad@binadarma.ac.id
}

\begin{abstract}
This study aims to determine the effect of the use of bamboo on concrete against compressive strength and specific gravity. Bamboo is used petung bamboo type with a size of 15-30 $\mathrm{mm}$. The variations in the use of bamboo in the specimens in the form of cubes $15 \mathrm{~cm} \times 15 \mathrm{~cm} \times 15 \mathrm{~cm}$ are $50 \%$ and $75 \%$ with the same shape and variations shape, from the weight of coarse aggregate. Based on the results there was a decrease in the value of the concrete slump along with the addition of the bamboo. Concrete absorption is marked by increased water absorption in concrete specimens which reaches $4,81 \%$. The decrease also occurred in the specific gravity and compressive strength of the specimen. The minimum value of average concrete density with bamboo substitution is $1902,2 \mathrm{~kg} / \mathrm{m}^{3}$ which found in bamboo specimens with $75 \%$ variation shape, and a maximum is $1991,1 \mathrm{~kg} / \mathrm{m}^{3}$ contained in bamboo specimens with the same shape of 50\% and variations shape 50\%. The maximum compressive strength is $135,1 \mathrm{~kg} / \mathrm{cm}^{2}$ which found in specimens with $50 \%$ bamboo shape variation and a minimum is 104,4 kg / cm2 which found in specimens with bamboo variation in shape of $75 \%$.
\end{abstract}

Keywords: Bamboo, type, compresive

\begin{abstract}
ABSTRAK
Penelitian ini bertujuan untuk mengetahui pengaruh penggunaan bambu pada beton terhadap kuat tekan dan berat jenis. Bambu yang digunakan berjenis bambu petung dengan ukuran 15-30 mm. Variasi dalam penggunaan bambu dalam benda uji berbentuk kubus $15 \mathrm{~cm} \times 15 \mathrm{~cm} \times 15 \mathrm{~cm}$ adalah $50 \%$ dan $75 \%$ dengan bentuk yang sama dan bentuk yang bervariasi, berdasarkan berat agregat kasar. Berdasarkan hasil pengujian terdapat penurunan nilai slump beton seiring dengan penambahan bambu. Penyerapan beton ditandai dengan peningkatan penyerapan air pada benda uji beton yang mencapai 4,81\%. Penurunan juga terjadi pada berat jenis dan kuat tekan benda uji. Nilai minimum berat jenis beton rata-rata dengan substitusi bambu adalah 1902,2 $\mathrm{kg} / \mathrm{m} 3$ yang ditemukan pada benda uji dengan variasi bentuk $75 \%$ bambu, dan maksimum adalah 1991,1 kg / m3 yang terkandung dalam benda uji pada bambu dengan bentuk yang sama 50\% dan variasi bentuk $50 \%$. Kekuatan tekan maksimum adalah $135,1 \mathrm{~kg} / \mathrm{cm} 2$ yang ditemukan pada benda uji dengan variasi bentuk bambu $50 \%$ dan minimum 104,4 $\mathrm{kg} / \mathrm{cm} 2$ yang ditemukan pada benda uji dengan variasi bambu dalam bentuk $75 \%$.
\end{abstract}

Kata kunci: Bambu, jenis, tekan 


\section{PENDAHULUAN}

Beton merupakan salah satu bahan konstruksi yang telah umum digunakan untuk bangunan gedung, jembatan, jalan, dan sebagainya [1]. Beton dibuat dengan cara mencampur agregat halus, agregat kasar, air, dan semen portland atau semen hidrolik yang lain. Inovasi beton selalu mengalami kemajuan dan perkembangannya selalu dituntut guna menjawab tantangan akan kebutuhan, beton yang akan dihasilkan diharapkan mempunyai kualitas tinggi meliputi kekuatan dan daya tahan tanpa mengabaikan nilai ekonomis [2]. Kebutuhan material beton dengan kualitas yang lebih baik untuk rancangan bangunan yang semakin tinggi dan bentang yang panjang memerlukan struktur yang ramping dan efisien [3]. Faktor efektifitas dan tingkat efisiensi merupakan hal-hal yang mendasari pemilihan dan penggunaan beton sebagai bahan konstruksi. Tingkat penggunaan beton semakin besar, namun bahan penyusun yang digunakan semakin mahal dan terbatas. Para peneliti telah banyak melakukan inovasi-inovasi bahan campuran beton untuk diuji coba agar bahan penyusunnya menjadi lebih ringan dan ekonomis. Pemakaian bahan organik dimaksudkan untuk meminimalisir dampak dari sifat beton yang kurang baik diantaranya memiliki berat jenis yang cukup tinggi sehingga akan menimbulkan efek pembebanan akibat beratnya sendiri [4]. Salah satu cara untuk meminimalisir beban statis adalah dengan mengganti agregat beton konvensional dengan agregat alternatif yang lebih ringan, sehingga berat jenis beton dapat direduksi dengan adanya pemakaian agregat alternatif tersebut [5]. Produk dari pemakaian agregat tersebut disebut dengan beton ringan. Pemakaian bambu sebagai pengganti agregat adalah salah satu usaha untuk mereduksi berat jenis beton [6].

Bambu memiliki kelemahan dalam usia pakai atau masa kelayanan yang relatif singkat akibat ekspose perubahan lingkungan, sehingga penggunaan bambu sebagai elemen struktur harus terlindung. Penggunaan agregat bambu memberikan konsekuensi penurunan pada nilai kuat tekan, karena bambu memiliki angka keausan dan kemampuan mengembang-menyusut yang tinggi, dan kekuatan struktur yang lebih rendah daripada agregat konvensional [4]. Untuk mengantisipasi penurunan kekuatan lebih jauh akibat adanya keterbatasan kekuatan bambu tersebut, maka ukuran agregat bambu dibuat dengan bentuk butiran yang bervariasi, dimaksudkan agar memiliki susunan agregat yang lebih rapat dan volume beton yang lebih padat. Penggunaan bambu sebagai agregat akan menghasilkan beton dengan beban statis yang lebih kecil dibandingkan dengan beton yang menggunakan agregat konvensional, dan pada akhirnya akan membuat konstruksi menjadi lebih ringan [7].

\section{METODE/ PERANCANGAN PENELITIAN}

Metode yang digunakan pada penelitian ini adalah kajian eksperimental. Sampel berupa benda uji kubus beton. Pengujian benda uji kubus beton yang dilakukan adalah pengujian kuat tekan dan akan dilakukan pada saat benda uji berumur 3, 7, 14, 21 \& 28 hari.

\subsection{Metode Penelitian}

Pada penelitian ini terdapat tahapan persiapan yaitu mempersiapkan bahan-bahan yang akan digunakan sebagai bahan campuran beton yang akan dibuat dan alat-alat yang akan dipakai dalam proses pembuatan benda uji beton. Alat-alat yang akan digunakan dalam pembuatan benda uji merupakan alat-alat yang dimiliki atau berasal dari Laboratorium Teknik Sipil Fakultas Tenik Universitas Bina Darma. Dalam penelitian ini bambu yang digunakan sebagai substitusi agregat kasar akan dipotong menjadi beberapa bentuk, yaitu berbentuk persegi, segitiga, persegi panjang dan bentuk sembarang (bentuk tak beraturan). Potongan-potongan bambu tersebut berukuran layaknya seperti ukuran agregat pada umumnya yaitu $1 / 1,1 / 2$, dan $2 / 3$. Hal ini bertujuan agar bambu dengan potongan yang ukurannya lebih kecil dapat mengisi kekosongan diantara agregat bambu yang lain 
dan juga untuk mengetahui pengaruh dari variasi bentuk agregat kasar terhadap kepadatan (density) beton yang pada akhirnya akan mempengaruhi nilai kuat tekan beton.

Setelah tahap persiapan selesai tahapan selanjutnya adalah tahap analisa bahan. Pada tahapan ini material penyusun beton berupa semen, air, agregat halus (pasir), agregat kasar (batu pecah) dan agregat kasar bambu dilakukan proses analisa bahan. Untuk agregat (pasir, batu pecah dan bambu) analisa bahan yang dilakukan meliputi analisa saringan, analisa kadar air, analisa berat isi, analisa kadar lumpur dan kandungan zat organis, analisa berat jenis dan absorbsi. Setelah proses analisa bahan selesai maka tahapan slanjutnya adalah pembuatan benda uji berdasarkan parameter dan variable penelitian. Setelah pembuatan benda uji selesai maka dilakukan pengujian kuat tekan berdasarkan umur beton yaitu 3, 7, 14, 21, 28 hari.

\subsection{Rumus dan Persamaan}

Cara menentukan nilai massa jenis beton :

$\rho=\frac{m}{V}$

Keterangan :

$\rho \quad=$ Massa jenis $\left(\mathrm{kg} / \mathrm{m}^{3}\right)$

$\mathrm{m} \quad=$ Massa $(\mathrm{kg})$

$\mathrm{V} \quad=$ volume $\left(\mathrm{m}^{3}\right)$

Cara menentukan nilai kuat tekan beton :

Kuat tekan $(\mathrm{K})=\frac{\mathrm{P}}{\mathrm{A}} \times 100$

Keterangan :

$\mathrm{K} \quad=$ Kuat tekan $\left(\mathrm{kg} / \mathrm{cm}^{2}\right)$

A $\quad=$ Luas penampang $\left(\mathrm{cm}^{2}\right)$

$\mathrm{P} \quad=$ Beban tekan $(\mathrm{kN})$

\section{HASIL DAN PEMBAHASAN}

Penelitian ini dilaksanakan di Laboratorium Teknik Sipil Universitas Bina Darma. Adapun tahapan-tahapan pelaksanaan pekerjaan yang sudah direncanakan dalam penelitian ini telah diselesaikan, seperti tahap analisa ayakan, analisa berat isi, analisa berat jenis, pengecekan kandungan air dalam agregat halus dan kasar, perhitungan campuran beton, pembuatan benda uji, perawatan benda uji, dan hingga dilaksanakannya pengujian kuat tekan. Dari tahapan-tahapan tersebut didapat data-data kasar yang selanjutnya akan dianalisis agar dapat mengetahui pengaruh dari penggunaan Bambu Petung sebagai substitusi agregat kasar terhadap massa jenis dan kuat tekan beton.

Untuk masing-masing agregat yang digunakan sebagai bahan penyusun beton yaitu pasir, batu pecah dan potongan bambu dilakukan pemeriksaan sebagai berikut:

a. Analisa ayakan

b. Pemeriksaan kadar lumpur

c. Pemeriksaan berat isi

d. Pemeriksaan berat jenis dan absorbsi 


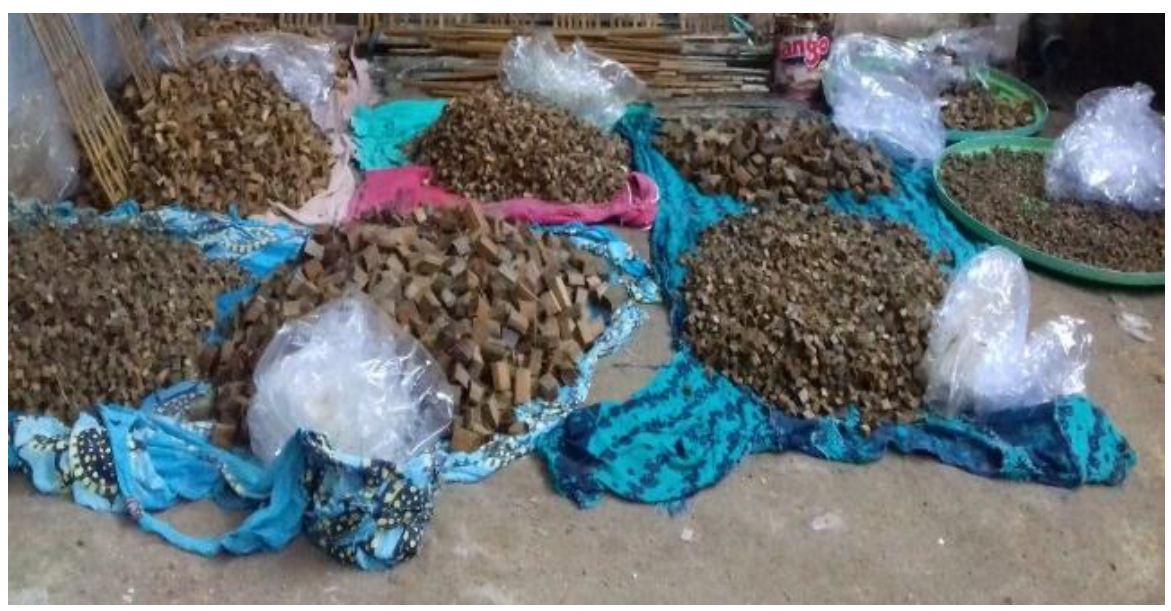

Gambar 1. Potongan agregat bambu berdasarkan ukuran

Adapun tahapan-tahapan yang dilakukan dalam proses pembuatan benda uji adalah sebagai berikut:

1) Perencanaan campuran beton

2) Persiapan alat dan bahan

3) Pembuatan benda uji

4) Pemeriksaan nilai Slump

5) Perawatan benda uji

Pada penelitian ini direncanakan beton dengan K-225 sehingga perencanaan campuran beton (Mix Design) benda uji kubus diuraikan sebagai berikut:

Panjang $(\mathrm{P})=15 \mathrm{~cm}$, lebar $(\mathrm{L})=15 \mathrm{~cm}$, tinggi $(\mathrm{T})=15 \mathrm{~cm}$, maka:

- Volume kubus

$$
\begin{aligned}
& =\mathrm{P} \times \mathrm{L} \times \mathrm{T} \\
& =0,15 \times 0,15 \times 0,15 \\
& =0,003375 \mathrm{~m}^{3} \\
& =15 \% \text { atau } 1,15 \\
& =0,003375 \times 1,15 \\
& =5 \times 0,003375 \times 1,15 \\
& =0,019406 \mathrm{~m}^{3}
\end{aligned}
$$

\begin{tabular}{|c|c|c|c|c|c|c|c|c|c|c|c|c|c|}
\hline \multirow[t]{3}{*}{ No. } & \multirow{3}{*}{$\begin{array}{c}\text { Kode Benda } \\
\text { Uji }\end{array}$} & \multicolumn{6}{|c|}{ Agregat Kasar } & \multirow{2}{*}{\multicolumn{5}{|c|}{$\begin{array}{c}\text { Umur uji } \\
\text { Kuat Tekan (hari) }\end{array}$}} & \multirow{3}{*}{$\begin{array}{c}\text { Jumlah } \\
\text { Benda } \\
\text { Uji }\end{array}$} \\
\hline & & \multicolumn{3}{|c|}{ Potongan Bambu } & \multicolumn{3}{|c|}{ Batu Pecah } & & & & & & \\
\hline & & $1 / 1$ & $1 / 2$ & $2 / 3$ & $1 / 1$ & $1 / 2$ & $2 / 3$ & 3 & 7 & 14 & 21 & 28 & \\
\hline 1 & BU-N & - & - & - & $30 \%$ & $40 \%$ & $30 \%$ & 1 & 1 & 1 & 1 & 1 & 5 \\
\hline 2 & BU-BBS50 & - & $50 \%$ & - & $25 \%$ & - & $25 \%$ & 1 & 1 & 1 & 1 & 1 & 5 \\
\hline 3 & BU-BBS75 & - & $75 \%$ & - & $10 \%$ & - & $15 \%$ & 1 & 1 & 1 & 1 & 1 & 5 \\
\hline 4 & BU-BBV50 & $10 \%$ & $30 \%$ & $10 \%$ & $20 \%$ & $10 \%$ & $20 \%$ & 1 & 1 & 1 & 1 & 1 & 5 \\
\hline 5 & BU-BBV75 & $30 \%$ & $20 \%$ & $25 \%$ & - & $20 \%$ & $5 \%$ & 1 & 1 & 1 & 1 & 1 & 5 \\
\hline \multicolumn{13}{|c|}{ Jumlah } & $25 \mathrm{bh}$ \\
\hline
\end{tabular}

- Faktor koreksi yg digunakan

Adapun parameter dan variabel benda uji sebagai berikut:

Tabel 1. Parameter, Variasi dan Jumlah Benda Uji

Sumber: Data penelitian, 2019 
Keterangan:
BU-N
: Benda Uji Normal
BU-BBS50 : Benda Uji Bambu Bentuk Sama 50\%
BU-BBS75 : Benda Uji Bambu Bentuk Sama 75\%
BU-BBV50 : Benda Uji Bambu Bentuk Variasi 50\%
BU-BBV75 : Benda Uji Bambu Bentuk Variasi 75\%

\section{A. Hasil Pengujian Berat Jenis}

Tabel 2. Hasil pengujian nilai berat jenis

\begin{tabular}{|c|c|c|c|c|c|c|c|c|}
\hline \multirow[t]{2}{*}{ Variasi } & Umur & $\mathbf{P}$ & $\mathbf{L}$ & $\mathbf{T}$ & Vol. & $\begin{array}{l}\text { Berat } \\
\text { Kering }\end{array}$ & $\begin{array}{l}\text { Berat } \\
\text { Jenis }\end{array}$ & $\begin{array}{c}\text { Berat } \\
\text { Jenis } \\
\text { Rata- } \\
\text { rata }\end{array}$ \\
\hline & (hari) & (m) & (m) & (m) & $\left(\mathrm{m}^{3}\right)$ & (kg) & $\left(\mathrm{kg} / \mathrm{m}^{2}\right)$ & $\left(\mathrm{kg} / \mathrm{m}^{2}\right)$ \\
\hline \multirow{5}{*}{ Normal } & 3 & 0,15 & 0,15 & 0,15 & 0,0034 & 7,9 & 2340,7 & \multirow{5}{*}{2299,3} \\
\hline & 7 & 0,15 & 0,15 & 0,15 & 0,0034 & 7,6 & 2251,9 & \\
\hline & 14 & 0,15 & 0,15 & 0,15 & 0,0034 & 7,6 & 2251,9 & \\
\hline & 21 & 0,15 & 0,15 & 0,15 & 0,0034 & 7,7 & 2281,5 & \\
\hline & 28 & 0,15 & 0,15 & 0,15 & 0,0034 & 8,0 & 2370,4 & \\
\hline \multirow{4}{*}{$\begin{array}{c}50 \% \\
\text { Bentuk } \\
\text { Sama }\end{array}$} & 3 & 0,15 & 0,15 & 0,15 & 0,0034 & 6,5 & 1925,9 & \multirow{5}{*}{1991,1} \\
\hline & 7 & 0,15 & 0,15 & 0,15 & 0,0034 & 6,8 & 2014,8 & \\
\hline & 14 & 0,15 & 0,15 & 0,15 & 0,0034 & 6,8 & 2014,8 & \\
\hline & 21 & 0,15 & 0,15 & 0,15 & 0,0034 & 6,8 & 2014,8 & \\
\hline & 28 & 0,15 & 0,15 & 0,15 & 0,0034 & 6,7 & 1985,2 & \\
\hline \multirow{5}{*}{$\begin{array}{c}75 \% \\
\text { Bentuk } \\
\text { Sama }\end{array}$} & 3 & 0,15 & 0,15 & 0,15 & 0,0034 & 6,8 & 2014,8 & \multirow{5}{*}{1914,1} \\
\hline & 7 & 0,15 & 0,15 & 0,15 & 0,0034 & 6,3 & 1866,7 & \\
\hline & 14 & 0,15 & 0,15 & 0,15 & 0,0034 & 6,5 & 1925,9 & \\
\hline & 21 & 0,15 & 0,15 & 0,15 & 0,0034 & 6,4 & 1896,3 & \\
\hline & 28 & 0,15 & 0,15 & 0,15 & 0,0034 & 6,3 & 1866,7 & \\
\hline \multirow{5}{*}{$\begin{array}{c}50 \% \\
\text { Bentuk } \\
\text { Variasi }\end{array}$} & 3 & 0,15 & 0,15 & 0,15 & 0,0034 & 6,5 & 1925,9 & \multirow{5}{*}{1991,1} \\
\hline & 7 & 0,15 & 0,15 & 0,15 & 0,0034 & 6,6 & 1955,6 & \\
\hline & 14 & 0,15 & 0,15 & 0,15 & 0,0034 & 6,6 & 1955,6 & \\
\hline & 21 & 0,15 & 0,15 & 0,15 & 0,0034 & 7,0 & 2074,1 & \\
\hline & 28 & 0,15 & 0,15 & 0,15 & 0,0034 & 6,9 & 2044,4 & \\
\hline \multirow{5}{*}{$\begin{array}{c}75 \% \\
\text { Bentuk } \\
\text { Variasi }\end{array}$} & 3 & 0,15 & 0,15 & 0,15 & 0,0034 & 6,3 & 1866,7 & \multirow{5}{*}{1902,2} \\
\hline & 7 & 0,15 & 0,15 & 0,15 & 0,0034 & 6,3 & 1866,7 & \\
\hline & 14 & 0,15 & 0,15 & 0,15 & 0,0034 & 6,3 & 1866,7 & \\
\hline & 21 & 0,15 & 0,15 & 0,15 & 0,0034 & 6,6 & 2014,8 & \\
\hline & 28 & 0,15 & 0,15 & 0,15 & 0,0034 & 6,6 & 1955,6 & \\
\hline
\end{tabular}




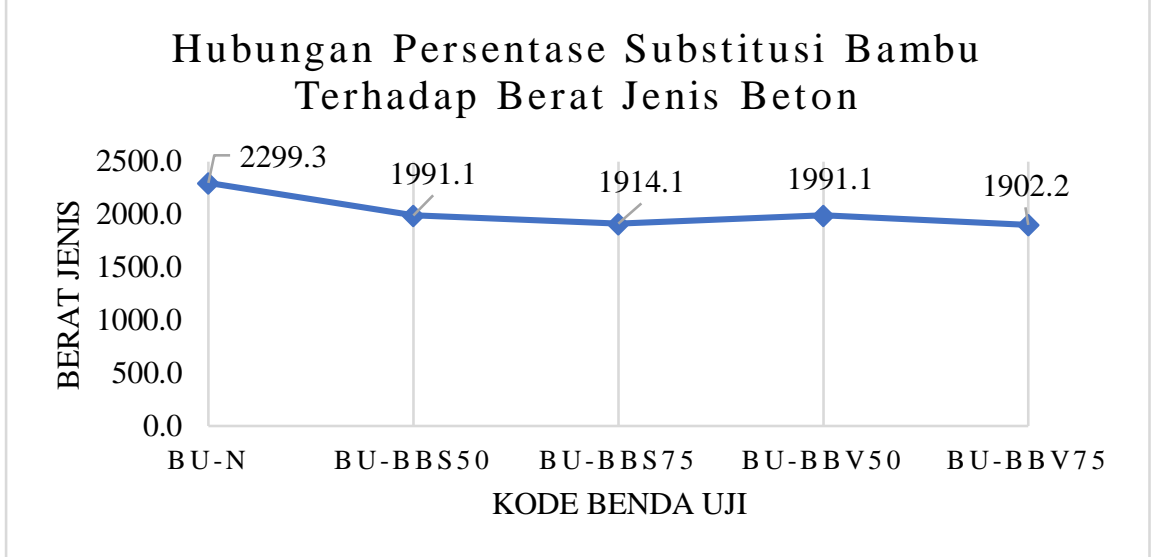

Gambar 2. Hubungan antara pemakaian substitusi bambu pada beton dengan berat jenis

Hasil perhitungan menunjukkan bahwa berat jenis rata-rata benda uji beton normal adalah $2299,3 \mathrm{~kg} / \mathrm{m}^{3}$. Untuk benda uji substitusi agregat kasar potongan bambu $75 \%$ bentuk variasi memiliki berat jenis rata-rata $1902,2 \mathrm{~kg} / \mathrm{m} 3$. Hal ini menunjukan terjadi penurunan berat jenis yang signifikan, dimana berat jenis rata-rata terkecil yang didapat sebesar $82,73 \%$ dari berat jenis rata-rata beton normal. Namun hasil ini masih belum memenuhi syarat beton ringan struktural, dimana disyaratkan berat jenis beton maksimum adalah $1680 \mathrm{~kg} / \mathrm{m} 3$ untuk kriteria beton ringan struktural (kombinasi agregat ringan dan pasir) (SNI 03-2461-2002). Persentase penurunan berat jenis rata-rata dari masing masing benda uji dengan substitusi potongan bambu terhadap beton normal dapat dilihat pada Tabel 3.

Tabel 3. Berat jenis rata-rata tiap benda uji dan persentase penurunannya

\begin{tabular}{|c|c|c|}
\hline $\begin{array}{c}\text { KODE BENDA } \\
\text { UJI }\end{array}$ & $\begin{array}{c}\text { BERAT JENIS } \\
\text { RATA-RATA }\end{array}$ & PERSENTASE \\
\hline BU-N & $2299,3 \mathrm{~kg} / \mathrm{m}^{3}$ & $100 \%$ \\
\hline BU-BBS50 & $1991,1 \mathrm{~kg} / \mathrm{m}^{3}$ & $86,60 \%$ \\
\hline BU-BBS75 & $1914,1 \mathrm{~kg} / \mathrm{m}^{3}$ & $83,25 \%$ \\
\hline BU-BBV50 & $1991,1 \mathrm{~kg} / \mathrm{m}^{3}$ & $86,60 \%$ \\
\hline BU-BBV75 & $1902,2 \mathrm{~kg} / \mathrm{m}^{3}$ & $82,73 \%$ \\
\hline
\end{tabular}

Pada Tabel 3 diatas diperoleh persentase berat jenis terkecil pada benda uji substitusi agregat kasar potongan bambu $75 \%$ bentuk variasi yaitu sebesar $82,73 \%$ dari berat jenis beton normal, atau dapat dikatakan terjadi penurunan terbesar $16,75 \%$ dari berat jenis beton normal untuk benda uji BUBBV75.

\section{B. Hasil Pengujian Kuat Tekan}

Pengujian kuat tekan beton dengan atau tanpa menggunakan substitusi potongan bambu petung dilakukan pada umur 3,7,14,21,28 hari. Pengujian kuat tekan beton pada penelitian ini dilakukan berdasarkan SNI 03-1974-1990. Hasil dari pengujian kuat tekan yang dihitung dengan menggunakan persamaan 4.6. Hasil dari pengujian benda uji kubus beton dari setiap variasi komposisi campuran dapat dilihat sebagai berikut: 
Tabel 4. Hasil pengujian kuat tekan benda uji gabungan/keseluruhan

\begin{tabular}{|c|c|c|c|c|}
\hline \multirow[t]{2}{*}{ Variasi } & Umur & $\begin{array}{l}\text { Beban } \\
\text { Tekan }\end{array}$ & $\begin{array}{c}\text { Luas } \\
\text { Penampang }\end{array}$ & $\begin{array}{l}\text { Kuat } \\
\text { Tekan }\end{array}$ \\
\hline & (hari) & $(\mathbf{k N})$ & $\left(\mathrm{cm}^{2}\right)$ & $\left(\mathrm{kg} / \mathrm{cm}^{2}\right)$ \\
\hline \multirow{5}{*}{ Normal } & 3 & 248 & 225 & 110,2 \\
\hline & 7 & 290 & 225 & 128,9 \\
\hline & 14 & 355 & 225 & 157,8 \\
\hline & 21 & 515 & 225 & 228,9 \\
\hline & 28 & 540 & 225 & 240,0 \\
\hline \multirow{5}{*}{$\begin{array}{c}50 \% \\
\text { Bentuk } \\
\text { Sama }\end{array}$} & 3 & 145 & 225 & 64,4 \\
\hline & 7 & 160 & 225 & 71,1 \\
\hline & 14 & 220 & 225 & 97,8 \\
\hline & 21 & 290 & 225 & 128,9 \\
\hline & 28 & 304 & 225 & 135,1 \\
\hline \multirow{5}{*}{$\begin{array}{c}75 \% \\
\text { Bentuk } \\
\text { Sama }\end{array}$} & 3 & 181 & 225 & 80,4 \\
\hline & 7 & 186 & 225 & 82,7 \\
\hline & 14 & 190 & 225 & 84,4 \\
\hline & 21 & 230 & 225 & 102,2 \\
\hline & 28 & 257 & 225 & 114,2 \\
\hline \multirow{5}{*}{$\begin{array}{c}50 \% \\
\text { Bentuk } \\
\text { Variasi }\end{array}$} & 3 & 135 & 225 & 60,0 \\
\hline & 7 & 205 & 225 & 91,1 \\
\hline & 14 & 210 & 225 & 93,3 \\
\hline & 21 & 223 & 225 & 99,1 \\
\hline & 28 & 240 & 225 & 106,7 \\
\hline \multirow{5}{*}{$\begin{array}{c}75 \% \\
\text { Bentuk } \\
\text { Variasi }\end{array}$} & 3 & 127 & 225 & 56,4 \\
\hline & 7 & 195 & 225 & 86,7 \\
\hline & 14 & 200 & 225 & 88,9 \\
\hline & 21 & 225 & 225 & 100,0 \\
\hline & 28 & 235 & 225 & 104,4 \\
\hline
\end{tabular}

Sumber: Hasil penelitian, 2019

Dari data tabel hasil pengujian kuat tekan tersebut, nilai kuat tekan paling tinggi dibawah benda uji beton normal dihasilkan oleh benda uji BU-BBS50 yaitu sebesar $135,1 \mathrm{~kg} / \mathrm{cm}^{2}$. Berdasarkan hasil yang didapat tersebut maka, semua benda uji yang dibuat merupakan beton nonstruktural karna persyaratan kuat tekan minimum untuk beton ringan struktural adalah $17 \mathrm{MPa} /$ K200 (SNI 03-2461-2002). Dengan demikian kuat tekan yang dihasilkan tidak memenuhi persyaratan. Sedangkan hasil pengujian kuat tekan beton untuk benda uji BU-BBS75, BU-BBV50 dan BU-BBV75 diperoleh kuat tekan masing-masing sebesar 114,2 kg/ $\mathrm{cm}^{2}, 106,7 \mathrm{~kg} / \mathrm{cm}^{2}$ dan 104,4 $\mathrm{kg} / \mathrm{cm}^{2}$. Nilai tersebut juga tidak memenuhi syarat kualifikasi kuat tekan untuk beton ringan struktural sesuai SNI 03-2461-2002. Dengan melihat hasil yang ditunjukkan pada tabel dan grafik dapat disimpulkan bahwa pemakaian substitusi bambu menyebabkan penurunan pada nilai kuat tekan. Penambahan substitusi bambu pada benda uji BU-BBS50, kuat tekannya sebesar $135,1 \mathrm{~kg} / \mathrm{cm}^{2}$ atau sekitar 56,30\% dari kuat beton normal dan untuk kuat tekan benda uji BU-BBV75 kuat tekannya sebesar $104,4 \mathrm{~kg} / \mathrm{cm}^{2}$, atau sekitar 43,52\% dari kuat tekan beton normal. 
Tabel 5. Persentase Penurunan kuat tekan tiap benda uji

\begin{tabular}{cccc}
\hline KODE BENDA UJI & \multicolumn{2}{c}{ KUAT TEKAN } & PERSENTASE \\
& & & \\
\hline BU-N & 240,0 & $\left(\mathrm{~kg} / \mathrm{cm}^{2}\right)$ & $100 \%$ \\
\hline BU-BBS50 & 135,1 & $\left(\mathrm{~kg} / \mathrm{cm}^{2}\right)$ & $56,30 \%$ \\
\hline BU-BBS75 & 114,2 & $\left(\mathrm{~kg} / \mathrm{cm}^{2}\right)$ & $47,59 \%$ \\
\hline BU-BBV50 & 106,7 & $\left(\mathrm{~kg} / \mathrm{cm}^{2}\right)$ & $44,44 \%$ \\
\hline BU-BBV75 & 104,4 & $\left(\mathrm{~kg} / \mathrm{cm}^{2}\right)$ & $43,52 \%$ \\
\hline & & \multicolumn{2}{c}{ Sumber: Hasil penelitian, 2019}
\end{tabular}

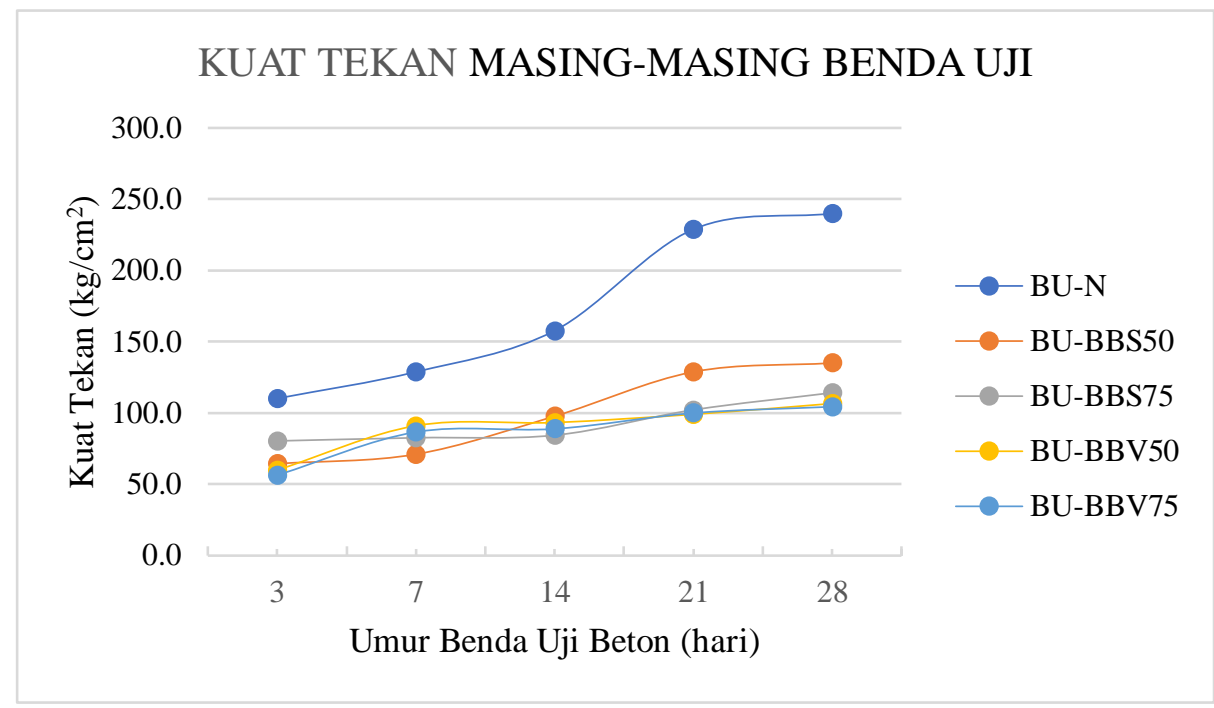

Gambar 3. Kuat tekan masing-masing benda uji

\section{KESIMPULAN DAN SARAN}

Penggunaan agregat bambu pada campuran beton sangat mempengaruhi kuat tekan yang dihasilkan, kuat tekan yang dihasilkan jauh lebih kecil dari nilai kuat tekan beton normal. Nilai kuat tekan paling tinggi sebesar $135,1 \mathrm{~kg} / \mathrm{cm}^{2}$ dan paling rendah sebesar $104,4 \mathrm{~kg} / \mathrm{cm}^{2}$, untuk nilai berat jenis minimum yang dihasilkan sebesar $1991,1 \mathrm{~kg} / \mathrm{m}^{3}$. Dari hasil nilai kuat tekan dan berat jenis benda uji dengan substitusi potongan bambu tersebut dapat diketahui bahwa nilai tersebut tidak memenuhi syarat kualifikasi kuat tekan dan berat jenis untuk beton ringan sesuai SNI 03-2461-2002. Penggunaan agregat bambu dengan bentuk variasi tidak begitu berpengaruh dalam hal meningkatkan nilai kuat tekan beton. Bahkan nilai kuat tekan benda uji dengan potongan bambu variasi lebih kecil dibanding benda uji dengan potongan bambu bentuk sama. Hasil penelitian yang telah dilakukan menunjukkan bahwa penggunaan agregat potongan bambu sebagai substitusi agregat kasar pada beton diperuntukkan untuk beton ringan yang digunakan pada konstruksi non struktural.

\section{DAFTAR PUSTAKA}

[1] A. Widodo, "Pengaruh Penggunaan Potongan Kawat Bendrat Pada Campuran Beton Dengan Konsentrasi Serat Panjang 4 Cm Berat Semen $350 \mathrm{Kg} / \mathrm{M} 3$ Dan Fas 0,5," J. Tek. Sipil dan Perenc., vol. 14, no. 2, pp. 131-140, 2016. 
[2] F. P. Pane, H. Tanudjaja, and R. S. Windah, "Pengujian Kuat Tarik Lentur Beton dengan Variasi Kuat Tekan Beton,” J. Sipil Statik, vol. 3, no. 5, pp. 313-321, 2015.

[3] S. Purwati, A, S. As'ad, "Pengaruh Ukuran Butiran Agregat Terhadap Kuat Tekan dan Modulus Elastisitas Beton Kinerja Tinggi Grade 80," e-Jurnal MATRIKS Tek. SIPIL, vol. 2, no. 2, pp. 58-63, 2014.

[4] M. H. Endarto, M.Riang \& Zulfiar, "Kajian Eksperimen Kuat Tekan Beton Ringan Menggunakan Agregat Bambu dan Bahan Tambah Beton,” J. Ilm. Semesta Tek., vol. 13, no. 1, pp. 12-20, 2010.

[5] A. Pujianto and M. Tajuddin, "Pengaruh Penggunaan Bambu Sebagai Pengganti Agregat Split terhadap Kuat Tekan Beton Ringan,” Ilm. Semesta Tek., vol. 15, no. 2, pp. 143-148, 2012.

[6] Rumanto, "Pengaruh Penggunaan Bambu Sebagai Agregat Kasar Terhadap Sifat Mekanik Beton Ringan," 2014.

[7] A. Wahono, "Aplikasi Agregat Ringan Untuk Meriduksi Berat Beton Komposit," Ilmu-Ilmu Tek., vol. 11, no. 1, pp. 57-66, 2008. 